Panee, C. D., \& Ballard, M. E. (2002). High versus low aggressive priming during video game training: Effects on game violence, state affect, heart rate, and blood pressure. Journal of Applied Social Psychology, 32(12): 24582474. (Dec 2002) Published by Wiley-Blackwell (ISSN: 1559-1816). DOI: 10.1111/j.1559-1816.2002.tb02751.x The definitive version is available at www3.interscience.wiley.com

\title{
High Versus Low Aggressive Priming During Video- Game Training: Effects on Violent Action During Game Play, Hostility, Heart Rate, and Blood Pressure
}

Cameron D. Panee and Mary E. Ballard

\begin{abstract}
Playing violent video games is related to increased negative affect and cardiovascular reactivity. We examined the influence of high and low aggressive priming during video-game training on violence during game play (e.g., shooting, choking), hostility, frustration with game play, blood pressure, and heart rate. Male undergraduates $(N=36)$ were assigned to a high aggressive or low aggressive video-game priming condition. After training, they played Metal Gear Solid ${ }^{\mathrm{TM}}$, which allows players to advance by using stealth, violence, or both. Participants in the high aggressive priming condition used significantly more violent action during game play and reported more hostility than those in the low aggressive priming condition. Heart rate was correlated with feelings of hostility. These findings indicate that both aggressive priming and use of game violence influence arousal and negative affect and might increase behavioral aggression.
\end{abstract}


"Cool! I just shot a cop and stole his car!" exclaimed the 23-year-old female student engrossed by Rockstar Game's Grand Theft Auto ${ }^{\text {TM }}$ on a Sony GameBoy ColorTMT. his popular game also allows players to run over pedestrians and hit motorists who "cut them off." Mounting concern about violent video games like Grand Theft Auto ${ }^{\mathrm{TM}}$ crested following intense media coverage of a rash of deadly school shootings. The news media reported that most of the shooters were aficionados of violent media, including violent video games. While it is doubtful that playing violent games can, by itself, result in that sort of violent behavior, there is evidence (e.g., Anderson \& Dill, 2000; Ballard \& Lineberger, 1999) that violent video-game play increases players' arousal and aggression.

In the present study, we use Konomi's tactical video game, Metal Gear Solid $^{\mathrm{TM}}$, where stealth and violence are used to progress through the game, to examine if the frequency of violent actions during game play (e.g., shooting or choking other characters) can be manipulated through priming during training and if this subsequently affects cardiovascular and state emotional reactions. Players were primed for video-game play by exposing them to training conditions where either (a) stealth could be used to hide from or sneak up on an opponent, but killing the opponent was necessary for mission success (high aggressive); or (b) stealth could be used to evade the opponent and killing the opponent was optional for mission success (low aggressive). Then, participants were assessed with regard to amount and type of violence used to progress in regular game play, cardiovascular reactivity during and following game play, and hostility and frustration following game play. In this article, we review the rapidly evolving video gaming industry, game content, behavioral correlates, and related theoretical issues.

\section{VIDEO-GAME TECHNOLOGY}

The video-game industry is the fastest growing media market (Levy, 2000). Over 150 million game consoles have been sold worldwide. The Sega Dreamcast ${ }^{\circledR}$, GameBoy Color $\AA$, and Playstation $2 \AA$ sold so rapidly following their release that there were shortages of these state-of-the-art machines (Elkin, 2000; Traiman, 2000). Personal computer games, interactive Internet games, and arcade games are also popular (Levy, 2000). This competitive, lucrative market has led to the evolution of sophisticated game systems and software. The Playstation $2 \circledR$ is so technologically capable that Japanese authorities restricted its export, fearing that it would be adapted into weapons technology (Joyce, 2000). Software for new consoles uses 3-D imaging and time-capture techniques to create lifelike characters and movement. Backgrounds and effects (including gore) are more realistic and multilayered, and they adapt to the game context. Some games use a first-person shooter vantage point that allows the player to be the game protagonist. Peripherals such as guns, steering wheels, and analogue controllers and vests that add tactile feedback to game play add to the realism of the games. The analogue controller for the Playstation $2 \circledR$ responds to the amount of pressure exerted on the keypad, adding nuance to game play by allowing the player to directly control the force of a strike or the speed of a race car.

Konomi's Metal Gear Solid ${ }^{\mathrm{TM}}$, the stimulus game for the present study, is a good example of the current technology. This highly rated ("The Fifty Best 
Games," 1999) strategy game has excellent graphics and movement (e.g., realistic fighting moves, blood) and employs inset maps, sophisticated weapons, radar warning screens, first- and third-person perspectives, cut scenes (animated clips that further the plot), and an analogue controller that vibrates when the player chokes an opponent in the game or uses explosives.

\section{VIDEO-GAME CONTENT}

While many types of video games are available, those with violent content are most popular. Boys report game violence to be a primary reason they enjoy playing video games (Barnett et al., 1997). Game violence is difficult to operationalize, as it varies in several ways: expression of violence (e.g., fighting, crashing cars, weapons), presence of blood and gore, the victim of violence (e.g., cartoon, alien, human), type of protagonist (e.g., human, cartoon, animal, alien), orientation of protagonist (i.e., prosocial or antisocial), perspective of protagonist (i.e., third person vs. first person), other available game strategies (e.g., stealth, cunning), and game atmosphere (e.g., horror, humor, sports). Funk, Flores, Buchman, and Germann (1999) and Walsh and Gentile (2001) found low reliability in rating video-game violence, particularly regarding games that have moderate levels of violence, cross genres (e.g., fighting games), or contain cartoon violence. As it is hard to equate high and low violence games on features of the game that are irrelevant to the hypothesis, but that might serve as confounds, it is difficult to design well-controlled studies. To overcome this methodological problem, we used one violent video game, with different priming training, as the stimulus for the present study.

Game content is increasingly explicit in terms of both violence and more recently, sex. As gamers have aged (58\% of console gamers are over 18 years of age, and 21\% are over 35 years; Croal, 2000), the number of female characters has increased and game content has become more sexual. Human characters, regardless of gender, are usually dressed in scanty, tight clothing. Most female characters have large breasts (Deitz, 1998), which may bounce as they run and jump during game play. A few games allow players to disrobe characters or to seek out sex. This trend is troubling, as media that combine sex and violence have a more profound negative impact on behavior (Donnerstein, 1983; Huesmann \& Malamuth, 1986; see Ballard \& Lineberger, 1999, for a review). Games with explicit content might receive a "Teen" or "Mature" rating, but without parental supervision, this system could backfire, as warning labels tend to increase interest in violent media (Bushman \& Stack, 1996). Another disturbing trend is for the game protagonist to be a "bad guy" (e.g., getaway-car driver, drug smuggler) rather than a "good guy" (e.g., police officer, alien hunter), although the impact of this shift has yet to be investigated.

\section{VIDEO GAMES, BEHAVIOR, AND THEORY}

The specific effects of violent video games differ depending on gender, measures, context, and game content. Van Schie and Wiegman (1 997; Wiegman \& Van Schie, 1998), who assessed 7th and 8th graders in The Netherlands, found 
that children who spent more time playing video games were less prosocial, but not more aggressive. Boys who preferred violent video games were both more aggressive and less prosocial. Further, while time spent playing video games per se was positively related to intelligence, time spend playing violent games was negatively related to intelligence. Anderson and Dill (2000) also reported a stronger link between playing violent video games and delinquency than time spent playing video games per se. This effect was stronger among those higher in trait negativity. Funk and Buchman (1 996), who examined seventh and eighth graders in the United States, found that time spent playing video games was negatively correlated to self-perceived competence (e.g., scholastic, social, athletic, worth) and behavioral problems in girls, but not in boys. Thus, violent game content, gender, and individual differences seem to moderate the interaction between video-game play and behavior.

Ballard and colleagues (Ballard \& Lineberger, 1999; Ballard \& Wiest, 1996) used a fighting game to examine responding among male undergraduates. Those who played Mortal Komba ${ }^{\mathrm{TM}}$ with blood and gore effects reported more hostility and had greater heart rate and systolic blood pressure reactivity than did those who played the game with no blood and gore or a control game (Ballard \& Wiest, 1996). Ballard, Panee, Engold, and Hamby (2001) found that blood pressure (BP) reactivity to video-game play decreased across a 3-week longitudinal study. Ballard and Lineberger found participants to display more aggression (immersion of a confederate's hand into a cold pressor device) and less prosocial behavior (candy reward) as game violence increased. Other studies have also found increased aggression (Anderson \& Dill, 2000) and decreased prosocial behavior (Chambers \& Ascione, 1987) following a violent, as opposed to a nonviolent, video game. Some studies have not found a relation between game violence and aggression (Scott, 1995; Winkel, Novak, \& Hopson, 1987). But, as games are not subjectively rated in terms of violence and differ as described earlier, one would expect some inconsistency across studies. Overall, a meta-analysis indicates that there are substantive cognitive and behavioral effects of violent video games (Anderson \& Bushman, 2001).

Theoretically, there are several reasons to expect that violent video-game play might be related to increased aggression. There is strong modeling and reinforcement of violence (Bandura, 1977) in video games; violence is rewarded with game progress, increases in power, additional weaponry, cut scenes, bonus points, and secret levels. While these rewards clearly increase game violence, it is unclear if or when this generalizes to other contexts. Game players generally report that they clearly differentiate between game play and real-life circumstances. Social cognitive models suggest that video games impact behavior via a combination of negative affect, arousal, cognitive scripts, and environmental priming. Video-game play often elicits anger and hostility (Anderson \& Ford, 1987; Ballard \& Lineberger, 1999; Ballard \& Wiest, 1996; Calvert \& Tan, 1994; Mehrabian \& Wixen, 1986), usually because of difficulty with the controller, repeated game failure, or repeated loss to an opponent. Any agitated negative affect, including hostility or frustration with game play, might result in aggression (Berkowitz, 1998; Canary, Spitzberg, \& Semic, 1998). However, cognitive mediation plays an important role in appraising and reacting to negative affect (Berkowitz, 1998; Canary et al., 1998; Huesmann, 1998), including that elicited by violent media (Anderson \& Dill, 2000; Bushman, 1996; Bushman \& Geen, 
1990; Huesmann \& Malamuth, 1986). Anderson and Dill proposed that violent video games increase the likelihood of aggression by modeling and priming aggressive scripts; increasing state hostility and physiological arousal; and, in the long run, leading to aggressive beliefs, perceptions, expectations, and behaviors.

The literature on video-game priming supports this thesis. Male and female undergraduates exposed to violent media display significantly lower reaction time in responding to aggressive words than do those exposed to nonviolent media (Anderson, Benjamin, \& Bartholow, 1998; Bushman, 1998b). Anderson et al. reported that students who were exposed to weapons (words or pictures) responded faster to aggressive words than did students who were exposed to names of animals or pictures of plants. Similarly, students who viewed an aggressive movie clip were faster in identifying aggressive words than were those who viewed a nonviolent movie clip (Anderson, 1997; Bushman, 1998b). Bushman (1 998b) also found that those who viewed a violent movie clip rated potentially aggressive homonyms (e.g., "cuff," "mug") as more aggressive than did those who viewed a nonviolent clip. Finally, Anderson and colleagues (Anderson \& Dill, 2000; Anderson \& Morrow, 1995) found that playing a violent video game primed aggressive thoughts and behaviors (including more game violence) significantly more than did a nonviolent game. Using two games equated on irrelevant variables, Anderson and Morrow manipulated instructions for game play (competitive vs. cooperative) and found that competitive instructions primed aggressive thoughts and increased violence during game play.

\section{STATEMENT OF PROBLEM AND HYPOTHESIS}

Violent video-game play primes aggressive cognitions and increases aggressionrelated behaviors (Anderson et al., 1998; Anderson \& Dill, 2000; Bushman, 1998b). Metal Gear Solid ${ }^{\top \mathrm{M}}$ differs from many other action/adventure games in that players can bypass enemy guards without harming them and succeed in game objectives. In fact, players receive higher scores if they avoid combat, rather than fight. However, several methods to attack and kill opponents are readily available. Using one game, to decrease potential confounds, we sought to determine if students who were primed to respond less aggressively (i.e,, stealth could be used without killing the guards to succeed in the training mission) or more aggressively (i.e., stealth could be used, but guards must be killed to succeed in the training mission) would differ in terms of subsequent violent action during game play, cardiovascular reactivity, and feelings of hostility. We hypothesize that high aggressive priming will result in more frequent violent action during game play and, subsequently, greater cardiovascular activity (i.e., heart rate and systolic and diastolic blood pressure), and higher levels of hostile feelings than will low aggressive priming.

\section{METHOD}

\section{Participants}

A complete data set was collected on 36 male undergraduates from a medium-sized southeastern university. The participants received extra course 
credit for participation. There were 3 potential participants who received credit, but were excluded from the study: 1 because the BP cuff was too small for his arm, 1 because the BP monitor malfunctioned during his session, and 1 because he ascertained the purpose of the study. Participants were primarily upper-middle class and White $(n=35,97 \%)$, and $1(3 \%)$ was African American. Mean age was 20.06 years. An equal number of participants $(N=18)$ were assigned to each of two groups.

\section{Apparatus}

Metal Gear Solid ${ }^{\mathrm{TM}}$, an action/adventure video game produced by Konomi, and a Sony Playstation were used as the apparatus for the experiment. In Metal Gear Solid, the player maneuvers the protagonist through a guarded military base to prevent a nuclear holocaust. A television and videocassette recorder were used to record participants' game performance. An automatic adult-sized BP cuff was used to monitor systolic blood pressure (SBP) and diastolic blood pressure (DBP) and heart rate (HR) four times: prior to training, after training, during game play, and immediately following game play.

\section{Measures}

Subscales from the Bell (1 962) Adjustment Inventory (BAI) were administered following game play. The BAl is a 200 -item Yes/No questionnaire with six subscales. We used the hostility subscale and included the items from the assertiveness and masculinity-femininity subscales as filler, for a total of 88 items.

The BAI hostility subscale correlates significantly $(r=35, p<.001)$ with the Buss-Durkee Hostility scale (Ballard \& Wiest, 1996), and it has excellent reliability (Sarbin, 1953). A demographic questionnaire was used to gather participants' age, ethnicity, and socioeconomic status. Participants' frustration with game play was assessed with the item, "How frustrating did you find you playing the game?" The item was rated on a 7-point scale ranging from 1 (not at all frustrating) to 7 (extreme frustration). 
Table 1

Coding Scheme for Game Attacks

\begin{tabular}{lclc}
\hline \multicolumn{1}{c}{ Game action } & $\begin{array}{c}\text { Hands-on } \\
\text { contact } \\
\text { (subscore) }\end{array}$ & \multicolumn{1}{c}{$\begin{array}{c}\text { Amount of damage } \\
\text { (subscore) }\end{array}$} & $\begin{array}{c}\text { Total } \\
\text { score }\end{array}$ \\
\hline Break the guard's neck & Yes (0.5) & Death (2) & 2.5 \\
Shoot the guard & No (0.0) & Death (2) & 2.0 \\
Choke the guard & Yes (0.5) & Unconsciousness (1.0) & 1.5 \\
Throw the guard & Yes (0.5) & Temporarily disabled (0.5) & 1.0 \\
Spar with the guard & Yes (0.5) & Falls down (0.0) & 0.5 \\
\hline
\end{tabular}

aScores for each attack were weighted depending on whether the attack was premeditated $(\times 2)$ or defensive $(\times 1)$.

Violent action during game play was coded from videotaped recordings by trained undergraduates who were blind to treatment condition. The first and last run through each of the five levels was coded. Segments varied in length as a result of individual differences in game play. We controlled for this by taking the number of guards encountered during each segment into consideration in the coding scheme. Five types of attack are possible in Metal Gear Solid ${ }^{\mathrm{TM}}$ : break the guard's neck, shoot the guard, choke the guard into unconsciousness, throw the guard, and spar with the guard. We used a mathematical formula to derive aggression scores for each attack, creating scores ranging from 0.5 to 2.5. Attacks were assigned point values based on hands-on contact and amount of damage inflicted (see Table 1 for coding). Scores were weighted depending on whether the attack was premeditated (x2) or defensive (x1). A premeditated attack was coded if a guard or camera had not detected the protagonist prior to an attack. Defensive attacks were coded when the protagonist's radar was jammed because of detection by a guard or camera. Weighted totals were divided by the number of guards encountered, yielding a score for violent actions during game play. Interrater reliability $(N=28)$ was .99 .

\section{Procedure}

Participants were run individually in 1-hr sessions. They were seated in a recliner in a lab furnished with a table and media cart. Each participant read and signed an informed consent form. They were told that they would be assessed on their performance on Metal Gear Solid ${ }^{\mathrm{TM}}$ and that their BP and HR would be monitored to examine the physiological effects of video-game play. They were informed that following game play, they would complete three questionnaires.

The BP cuff was attached and, after a 5-min adaptation period, resting BP and 
HR measures were taken. The game controller, screen features, and commands (including all attacks) were explained to the participants, and the participants were given time to become familiar with controller movements and commands (about $1 \mathrm{~min}$ ). Metal Gear Solid ${ }^{\mathrm{TM}}$ was set to the virtual reality training mode. All participants, regardless of condition, played five training mode levels to allow them to become familiar with the character's movements and abilities and the context of the game. During the familiarization period all strategies were available for use, and participants were given no instructions regarding the use of stealth versus attack. The objective of each training level (i.e., move from the elevator to the left end of the corridor) was printed on the screen at the beginning of the level. Participants were given 2 min to play each level.

After the familiarization period, participants in the high aggressive condition were told to enter the gun-shoot training mode (Levels 1, 2, and 3 were completed). They were instructed "These training levels are identical to the previous five, except that you must kill the guards in order to have the completion cone appear. You have a gun and the amount of ammunition stated in the instructions." After the familiarization period participants in the low aggressive condition were told to enter the time attack training mode (Levels 1, 2, and 3 were completed). They were instructed, "These training levels are identical to the previous five. You do not have to kill the guards to complete these levels, but it is still an option." BP and HR measures were taken after the participants in both conditions completed the training levels.

Next, Metal Gear Solid ${ }^{\mathrm{TM}}$ as set to the first of five game scenarios. For each game scenario, participants were given a specific objective in terms of moving the character from one area to another. Participants were told "You will be given 5 minutes to complete each level. Instructions will be given at the beginning of each level." Since killing the guards was not required in the game scenarios, participants in the high aggressive condition were also instructed, "You do not have to kill the guards to complete these levels, but it is still an option." Participants were given the goal for the first level (i.e,, "Exit the elevator and go to each of the four corners in the room you enter. Then return to the elevator."). After the participant completed the level or ran out of time, he was given the objective for the next scenario and reminded that he had $5 \mathrm{~min}$ to reach the objective. This process was repeated until the participant completed all five game scenarios. BP and HR measures were taken after the third scenario and after completion of game play. Then, participants were given the questionnaire packet and instructions. After completing the questionnaires, each participant was debriefed, given a credit slip, and thanked for his participation.

\section{RESULTS}

First, a MANOVA was used to examine the effect of the independent variable (high vs. low aggressive priming condition) on three dependent variables: scores of violent action during game play, feelings of hostility, and feelings of frustration with game play. The MANOVA was significant, with Hotelling's trace $F(3,32)=$ 22.20, $p<.001$, partial $\mathrm{n}^{2}=.67$ (see Table 2 for means, standard deviations, and 172 for each dependent measure; see Table 3 for zero-order correlations between all dependent measures and partial correlations controlling for condition). 
Univariate follow-up tests indicate that violent action during game play varied significantly with priming condition, $F(I, 34)=59.17, p<.001$. Those in the high aggressive priming condition used significantly more violent actions during game play than did those in the low aggressive condition. A substantial portion (64\%) of the variance in violent actions during game play was accounted for by priming condition. Hostility scores also varied by priming condition, $F(1,34)=$ $20.69, p<.001$. Participants in the high aggressive priming condition reported significantly higher hostility than did participants in the low aggressive priming condition. Despite this, there were no main effects of priming condition on reported feelings of frustration with game play.

Table 2

Discipline Statistics and Outcome Measures for High and Low Aggressive VideoGame Priming

\begin{tabular}{lrrrrrr}
\hline & \multicolumn{3}{c}{$\begin{array}{c}\text { High aggressive } \\
\text { priming }\end{array}$} & & & \multicolumn{3}{c}{ Low aggressive priming } \\
\cline { 2 - 3 } \cline { 7 - 8 } \multicolumn{1}{c}{ Variable } & \multicolumn{1}{c}{$M$} & $S D$ & & \multicolumn{1}{c}{$M$} & \multicolumn{1}{c}{$S D$} & $\eta^{2}$ \\
\hline Violent actions & $2.57^{* * * *}$ & 0.61 & & 1.15 & 0.49 & .64 \\
Hostility & $17.06^{* * *}$ & 2.84 & & 11.78 & 4.02 & .38 \\
Frustration & 3.44 & 1.50 & & 3.78 & 1.40 & .01 \\
HR during game play & 73.55 & 10.76 & & 80.58 & 12.02 & .01 \\
SBP during game play & 126.44 & 10.27 & & 125.83 & 10.59 & .04 \\
DBP during game play & 76.27 & 7.93 & & 76.66 & 8.45 & .00 \\
\hline
\end{tabular}

Note. $\mathrm{HR}=$ heart rate, $\mathrm{SBP}=$ systolic blood pressure, $\mathrm{DBP}=$ diastolic blood pressure. ${ }^{* * *} p<.001$.

For the resting cardiovascular measures, we used $t$ tests (one each for SBP, $\mathrm{DBP}$, and HR) to ensure that there were no preexisting differences between priming conditions. Resting SBP and DBP were similar for participants in the two conditions ( $p s>30$ ). While HR did not differ significantly between conditions, there was a strong trend in that direction, $\mathrm{t}(34)=1.97, \mathrm{p}=.06$. Participants in the high aggressive priming condition had somewhat resting lower HRs ( $M=73.11$, $S D=10.06)$ than did those in the low aggressive priming condition $(M=81.00$, $S D=13.64)$.

Cardiovascular reactivity was analyzed separately for training and game play. For training, three separate one-way ANCOVAs were run on SBP, DBP, and HR. Priming condition was the independent variable; and resting SBP, resting DBP, and resting HR, respectively, served as the covariates. These analyses were not significant (allps > .40).

Averages were calculated for SBP, DBP, and HR using the measures taken during and immediately following game play. Three one-way ANCOVAs were 
run on average SBP, DBP, and HR, with priming condition as the independent variable and the appropriate resting cardiovascular measure as the covariate. Priming condition was not related to significant differences in the cardiovascular measures (all ps > .30).

Table 3

Zero-Order Partial Correlations Between Outcome Variables

\begin{tabular}{lcccccccccccc}
\hline & 1 & 2 & 3 & 4 & 5 & 6 & 7 & 8 & 9 & 10 & 11 & 12 \\
\hline 1. Violent actions & - & $.56^{* *}$ & -.23 & .09 & .16 & .22 & -.08 & .15 & .20 & -.14 & .00 & .10 \\
2. Hostility & .15 & - & .20 & .04 & -.05 & .18 & -.13 & -.16 & $.36^{*}$ & -.13 & -.08 & .21 \\
3. Frustration & -.23 & $.34^{*}$ & - & -.03 & .04 & $.39^{*}$ & -.01 & -.11 & $.37^{*}$ & -.13 & -.04 & $.39^{*}$ \\
4. Resting SBP & -.06 & -.07 & -.01 & - & $.42^{* *}$ & .23 & $.65^{* *}$ & .27 & .14 & $.69^{* *}$ & $.36^{*}$ & .07 \\
5. Resting DBP & .16 & -.13 & .05 & $.41^{*}$ & - & $.54^{* *}$ & .19 & $.76^{* *}$ & .12 & .12 & .70 & .17 \\
6. Resting HR & -.06 & -.02 & $.46^{* *}$ & .19 & $.55^{* *}$ & - & .07 & $.34^{*}$ & $.71^{*}$ & .04 & $.57^{* *}$ & $.72^{* *}$ \\
7. Training SBP & -.18 & -.18 & -.01 & $.65^{* *}$ & .19 & .06 & - & .08 & .08 & $.79^{* *}$ & .14 & -.02 \\
8. Training DBP & .17 & -.26 & -.11 & .26 & $.76^{* *}$ & $.34^{*}$ & .08 & - & .05 & .05 & $.59^{* *}$ & -.06 \\
9. Training HR & -.09 & .23 & .43 & .10 & .10 & $.68^{* *}$ & .08 & .03 & - & .11 & $.33^{*}$ & $.85^{*}$ \\
10. Game play SBP & -.19 & -.14 & -.14 & $.71^{* *}$ & .12 & .05 & $.79^{* *}$ & .04 & .13 & - & .22 & -.06 \\
11. Game play DBP & -.02 & -.12 & -.04 & $.36^{*}$ & $.69^{* *}$ & $.59^{* *}$ & .14 & $.58^{* *}$ & $.33^{*}$ & .23 & - & $.42^{* *}$ \\
12. Game play HR & -.23 & .03 & $.45^{* *}$ & .02 & .16 & $.69^{* *}$ & -.03 & .09 & $.84^{*}$ & -.05 & $.43^{* *}$ & - \\
\hline
\end{tabular}

Note. Correlations above the diagonal are zero-order correlations and those below the diagonal are zero-order partial correlations controlling for condition. SBP = systolic blood pressure, $\mathrm{DBP}=$ diastolic blood pressure, $\mathrm{HR}=$ heart rate.

${ }^{*} p<.05 .{ }^{* *} p<.01$.

Finally, we examined cardiovascular reactivity across the course of the session.

For each cardiovascular measure, we performed a within-subjects, repeated measures

ANOVA. As there was no between-subjects factor, no covariate was

necessary. Changes in arousal are indicated by a moderate increase in DBP, F(3, $33)=3.55,=.07$; and a significant decrease in $\operatorname{SBP}, F(3,33)=4.17,<.01$, across time. Pairwise comparisons (see Table 4 for means and standard deviations) show that DBP was marginally higher during the first $(p=.08)$ and second 
$(p=.06)$ play measures than during the resting measure. With regard to SBP, the measure taken immediately following cessation of game play was significantly lower than was SBP during rest $(p<.001)$, training $(p<$. 0l $)$, or the first game play measure $(p<.05)$.

Table 4

Descriptive Statistics for Cardiovascular Variables Across Time

\begin{tabular}{|c|c|c|c|c|c|c|c|c|c|}
\hline & \multicolumn{2}{|c|}{ Resting } & \multicolumn{2}{|c|}{ Training } & \multicolumn{2}{|c|}{ Game Play 1} & \multicolumn{3}{|c|}{ Game Play 2} \\
\hline & $M$ & $S D$ & $M$ & $S D$ & $M$ & $S D$ & $M$ & $S D$ & $\eta^{2}$ \\
\hline SBP & $129.22 * *$ & 1.97 & 128.44 & 1.97 & 127.53 & 1.88 & 124.75 & 1.76 & .28 \\
\hline DBP & $74.31 \dagger$ & 8.03 & 75.39 & 6.77 & 76.39 & 8.27 & 76.56 & 8.91 & .09 \\
\hline HR & 77.05 & 12.47 & 78.33 & 12.09 & 76.41 & 11.75 & 77.72 & 12.86 & .08 \\
\hline
\end{tabular}

Note. $\mathrm{SBP}=$ systolic blood pressure, $\mathrm{DBP}=$ diastolic blood pressure, $\mathrm{HR}=$ heart rate. $\dagger p=.07 .{ }^{* *} p<.01$.

\section{DISCUSSION}

The hypotheses were partially supported. Aggressive priming during videogame training affected the use of violent action during game play (e.g., shooting, choking other characters) and feelings of hostility. In turn, use of violent action during game play affected feelings of hostility and SBP. Both SBP and DBP changed across the course of game play.

The most noteworthy finding is that we were able to manipulate the frequency of violent action during game play. Although stealth is a more expedient way to advance through Metal Gear Solid ${ }^{\mathrm{TM}}$ than is game violence, the ability to attack (via guns or martial prowess) was readily available to all players throughout the session, regardless of priming condition. While all players used some violent techniques in progressing through Metal Gear Solid ${ }^{\mathrm{TM}}$, participants who were given the option not to kill during game training used covert techniques to a higher degree, and violence to a lesser degree, than did those who were required to kill during training. Thus, even though the necessity of killing was removed in actual game play for those in the more aggressive condition, they continued to use more violent actions during game play; that is, they were much more likely to attack or kill guards than were those in the less aggressive priming condition. This is consistent with the thesis that exposure to a situation where aggression is required makes aggressive reactions more accessible (e.g., Bushman, 1998b; Josephson, 1987) and extends Anderson and Morrow's (1995) findings.

Both priming condition and use of violent actions during game play affected levels of hostility after game play. Those exposed to the high aggressive priming training displayed higher levels of hostility following game play than did those in the low aggressive priming condition. Further, participant use of violent action 
during game play per se was strongly related to feelings of hostility (Table 2). However, despite this, violent action during game play was moderately but not significantly negatively correlated with frustration. Thus, the results are particularly compelling, as hostility rather than frustration per se was related to aggression.

While none of the cardiovascular measures were affected by priming condition, there are several interesting cardiovascular effects. HR differed marginally between groups during baseline. We found effects for cardiovascular measures over time: Participants' SBP decreased and their DBP increased across the course of game play. This is similar to the findings of Ballard et al. (200 I), who examined cardiovascular measures over a longer period of game play and found that SBP decreased significantly at the beginning of game play and increased significantly only after the cessation of game play. Ballard et al. did not find significant changes in DBP across game play, but cardiovascular measures are often differentially reactive to stimuli (El-Sheikh, Ballard, \& Cummings, 1994; NcNamara \& Ballard, 1999). Further, stimulus differences might also affect cardiovascular reactivity. For example, the game stimulus used in this study did not include gore, but the game stimuli used by Ballard and Wiest (1996) and Ballard et al. included high levels of gore. Cardiovascular measures are often differentially reactive to stimuli (e.g., McNamara \& Ballard, 1999). So, blood and gore, use of stealth versus violence, and so forth might elicit different behavioral and physiological reactions during game play. Further, the protagonist in Metal Gear Solid ${ }^{\mathrm{TM}}$ is a good guy, which might elicit different reactions than an antisocial protagonist. Future research should continue to explore these differences in game content and context. For example, subsequent research should investigate the impact of game violence that is aimed at ameliorating social ills versus game violence that is perpetrated for its own sake or for illicit gain.

The strength of this study lies in its design-the use of one game and multiple measures to examine the impact of violent video-game play. There are a few limits of the study that need to be addressed. First, the participants were run through a single session. As the cumulative effects of video-game play are in question, we recommend more brief longitudinal studies, such as that of Ballard et al. (2001), to examine these effects. Second, the sample was small and participants were limited in terms of demographic characteristics-most of the participants were White, middle-class youth.

While this restricted sample limits the generalizability of the results, most of the media attention on the negative impact of video games has focused on this demographic, so there are practical implications for this sample. Further, the empirical evidence regarding television has generalized well across age groups and cohorts, so it is likely that these findings will hold up similarly. However, as people across age, ethnic, and gender lines are becoming garners, we need to examine the issues related to the impact of video games across a variety of participants. Third, the issue of defining and rating video-game violence is problematic. In this study, the use of violence and stealth were confounded to a degree, although using the same game context removes most of the other confounds tied to the problem of operationalizing game violence. Finally, subsequent studies should include behavioral measures of aggression, such as the cold pressor (Ballard \& Lineberger, 1999) or finger press (Rainwater \& McNeil, 1991), and 
should employ newer pencil-and-paper measures of hostility (e.g., Anderson \& Morrow, 1995) and aggression (e.g., Buss \& Warren, 2000).

In summary, our results indicate that violent actions during game play can be manipulated by priming; both the level of aggression of the priming condition and participant violence during game play affected feelings of hostility. Our findings add to the general pattern of results suggesting that video-game violence increases arousal and negative affective responding and that this is likely to influence subsequent behavior, including aggression (Anderson \& Dill, 2000). Further, our findings add to the larger body of evidence that, in general, media violence, including video games, movies, and televised violence might have detrimental effects on viewers across domains of functioning. Not only does media violence affect priming, hostility, and aggression (e.g., Eron \& Huesmann, 1987; Rule \& Ferguson, 1986), it also influences memory for program content (e.g., Bushman, 1998a), fear (Potter \& Smith, 2000), attitudes toward women and rape (e.g., Linz, Donnerstein, \& Penrod, 1984), and physiological and behavioral desensitization (Ballard et al., 2001; Cline, Croft, \& Courrier, 1973; Thomas, Horton, Lippencott, \& Drabman, 1977).

Practically speaking, it seems clear that playing violent video games increases the likelihood of aggressive responses. Ideally, software designers would recognize this and create fewer aversively violent games and more games that include alternatives to violence for game success. However, it is unlikely, given the economic benefits of producing violent games and the protection of the Constitution, that this change in philosophy will come about. In fact, there has been a recent call for games to "grow up," in terms of sex and violence, given the increasing numbers of adult gamers (Russo, 2001). Thus, it is imperative that the Entertainment Software Ratings Board (ESRB) refines and publicizes the game rating system that is now in place (Walsh \& Gentile, 2001).

In addition, retailers should implement a system to ensure that ESRB ratings are heeded, so that games meant for mature audiences are not sold to children and teens. Finally, and most importantly, parents should be familiar with the media consumption of their children and monitor this consumption, such that their children are not exposed to developmentally inappropriate material.

\section{REFERENCES}

Anderson, C. A. (1997). Effects of violent movies and trait irritability on hostile feelings and aggressive thoughts. Aggressive Behavior, 23, 161 - 178.

Anderson, C. A., Benjamin, A. J., Jr., \& Bartholow, B. D. (1998). Does the gun pull the trigger? Automatic priming effects of weapon pictures and weapon names. Psychological Science, 9,308-3 14.

Anderson, C. A., \& Bushman, B. J. (2001). Effects of violent video games on aggressive behavior, aggressive cognition, aggressive affect, physiological arousal, and prosocial behavior: A meta-analytic review of the scientific literature. Psychological Science, 12, 353-359. 
Anderson, C. A., \& Dill, K. E. (2000). Video games and aggressive thoughts, feelings, and behavior in the laboratory and in life. Journal of Personality and Social Psychology, 78, 772-790.

Anderson, C. A., \& Ford, C. M. (1987). Affect of the game player: Short-term effects of highly and mildly aggressive video games. Personality and Social Psychology Bulletin, 12, 390-401.

Anderson, C. A., \& Morrow, M. (1995). Competitive aggression without interaction: Effects of competitive versus cooperative instructions on aggressive behavior in video games. Personality and Social Psychology Bulletin, 21,390-401.

Ballard, M. E., \& Lineberger, R. (1999). Video game violence and confederate gender: Effects on reward and punishment among college males. Sex Roles, 41, 541-558.

Ballard, M. E., Panee, C. D., Engold, E. D., \& Hamby, R. H. (2001, April). yiolent video game play, cardiovascular reactivity, affective responses, and uggression: A brief longitudinal study. Presented at the Society for Research in Child Development, Minneapolis, MN.

Ballard, M. E., \& Wiest, J. R. (1 996). Mortal Kombat ${ }^{\mathrm{TM}}$ : The effects of violent videogame play on males' hostility and cardiovascular responding. Journal of Applied Social Psychology, 26, 7 17-730.

Bandura, A. (1977). Social learning theory. Englewood Cliffs, NJ: Prentice-Hall.

Barnett, M. A., Vitaglione, G. D., Harper, K. G., Quackenbush, S. W., Steadman, L. A., \& Valdez, B. S. (1997). Late adolescents' experiences with and attitudes toward videogames. Journal of Applied Social Psychology, 27, 1316- 1334.

Bell, H. M. (1962). Bell Adjustment inventory. Palo Alto, CA: Consulting Psychologists Press.

Berkowitz, L. ( 1989). Frustration-aggression hypothesis: Examination and reformulation. Psychological Bulletin, 106, 59-73.

Bushman, B. J. (1996). Individual differences in the extent and development of aggressive cognitive-associative networks. Personality and Social Psychology Bulletin, 22, 811-819.

Bushman, B. J. (1998a). Effects of television violence on memory for commercial messages. Journal of Experimental Psychology: Applied, 4,291 -307.

Bushman, B. J. (1998b). Priming effects of media violence on the accessibility of aggressive constructs in memory. Personality and Social Psychology Bulletin,24, 537-545.

Bushman, B. J., \& Geen, R. G. (1990). Role of cognitive-emotional mediators and individual differences in the effects of media violence on aggression. Journal of Personality and Social Psychology, 58, 156- 163. 
Bushman, B. J., \& Stack, A. D. (1996). Forbidden fruit versus tainted fruit: Effects of warning labels on attraction to television violence. Journal of Experimental Psychology: Applied, 2,207-226.

Buss, A. H., \& Warren, W. L. (2000). Aggression questionnaire. Los Angeles, CA: Western Psychological Services.

Calvert, S. L., \& Tan, S. ( 1994). Impact of virtual reality on young adults' physiological arousal and aggressive thoughts: Interaction versus observation.

Journal of Applied Developmental Psychology, 15, 125-139.

Canary, D. J., Spitzberg, B. H., \& Semic, B. A. (1998). The experience and expression of anger interpersonal settings. In P. A. Anderson \& L. K.

Ciuerrero (Eds.), Handbook of communication and emotion: Research, theory, applications, and contexts (pp. 189-2 13). San Diego, CA: Academic Press.

Chambers, J. H., \& Ascione, F. R. (1 987). The effects of prosocial and aggressive videogames on children's donating and helping. Journal of Genetic Psycholology, 148, 499-505.

Cline, V. B., Croft, R. G., \& Courrier, S. (1973). Desensitization of children to television violence. Journal of Personality and Social Psychology, 27, 360-365.

Croal, N. (2000, June 12). The art of darkness. Newsweek, 135(24), 48-49.

Deitz, T. L. (1 998). An examination of violence and gender role portrayals in video games: Implications for gender socialization and aggressive behavior. Sex Roles, 38, 425-442.

Donnerstein, E. (1983). Erotica and human aggression. In R. Geen \& E. Donnerstein (Eds.), Aggression: Theoretical and empirical reviews (pp. 242-255).

New York, NY Academic Press.

Elkin, T. (2000, February 14). Dreamcast system brings Sega back into contention. Advertising Age, 71(7), 17- 19.

El-Sheikh, M., Ballard, M., \& Cummings, E. M. (1994). Individual differences in preschoolers' physiological and verbal responses to videotaped angry interactions. Journal of Abnorma1 Child Psychology, 22, 303-320.

Eron, L. D., \& Huesmann, L. R. (1 987). Television as a source of maltreatment of children. School Psychology Review, 16, 195-202.

Funk, J. B., \& Buchman, D. D. (1996). Playing violent video and computer games and adolescent self-concept. Journal of Communication, 46, 19-32.

Funk, J. B., Flores, G., Buchman, D. D., \& Germann, J. N. (1999). Rating electronic games: Violence is in the eye of the beholder. Youth and Society, 30, 283-312. 
Huesmann, L. R. (1 998). The role of social information processing and cognitive schema in the acquisition and maintenance of habitual aggressive behavior. In R. G. Geen \& E. Donnerstein (Eds.), Human aggression (pp. 73-109). San Diego, CA: Academic Press.

Huesmann, L. R., \& Malamuth, N. M. (1986). Media violence and antisocial behavior: An overview. Journal of Social Issues, 42, 1-6.

Josephson, W. L. ( 1987). Television violence and children's aggression: Testing the priming, social script, and disinhibition predictions. Journal of Personality and Social Psychology, 53,882-890.

Joyce, C. (2000, April 17). International: Game console "could be used in missiles." Daily Telegraph (London), p. 11.

Levy, S. (2000, March 6). Here comes Playstation 2. Newsweek, 135(10), 54-59.

Linz, D., Donnerstein, E., \& Penrod, S. (1984). The effects of multiple exposures to filmed violence against women. Journal of Communication, 34(3),

McNamara, L., \& Ballard, M. E. (1999). Resting arousal, sensation seeking, and music preference. Genetic, Social, and General Psychology Monographs, $125,229-250$.

Mehrabian, A., \& Wixen, W. J. (1986). Preferences for individual video games as a function of their emotional effects on players. Journal of Applied Social Psychology, 16, 13-15.

Potter, J. W., \& Smith, S. (2000). The context of graphic portrayals of television violence. Journal of Broadcasting and Electronic Media, 44, 30 1-323.

Rainwater, A. J., \& McNeil, D. W. (1 991 ). Reinventing the algometer: Synopsis of the literature and presentation of a reliable, inexpensive model. Behavior Research Methods, instruments, and Computers, 23,486-492.

Rule, B. G., \& Ferguson, T. J. (1986). The effects of media violence on attitudes, emotions, and cognitions. Journal of Social issues, 43(3), 29-50.

Russo, T. (2001, February). Games grow up. NextGen Magazine, 54-60.

Sarbin, T. R. (1 953). Review of the Adjustment Inventory. In 0. K. Buros (Ed.), The fourth mental measurement yearbook (Vol. 130, p. 357). Highland Park, NJ: Gryphon.

Scott, D. (1995). The effect of video games on feelings of aggression. Journal of Psychology Interdisciplinary and Applied, 129, 121 - 132.

Thomas, M. H., Horton, R. W., Lippencott, E. C., \& Drabman, R. S. (1977). Desensitization to portrayals of real-life aggression as a function of exposure to television violence. Journal of Personality and Social Psychology, 35, 450-458. 
Traiman, S. (2000, January 29). Shortages hurt video, PC game sales. Billboard, 112(5), 67-68.

van Schie, E. G., \& Wiegman, 0. (1997). Children and videogames: Leisure activities, aggression, social integration, and school performance. Journal of Applied Social Psychology, 27, 1175- 1194.

Walsh, D. A., \& Gentile, D. A. (2001). A validity test of movie, television, and video-game ratings. Pediatrics, 107, 1302-1 308.

Wiegman, O., \& van Schie, E. G. (1998). Video game playing and its relations with aggressive and prosocial behavior. British Journal of Social Psychology, 37, 367-378.

Winkel, M., Novak, D. M., \& Hopson, H. (1987). Personality factors, subject gender, and the effects of aggressive video games on aggression in adolescents. Journal of Research in Personality, 21, 211-223. 